\title{
EVALUATION OF SUBDERMAL BIODEGRADABLE IMPLANTS INCORPORATING RIFAMPICIN AS A METHOD OF DRUG DELIVERY IN EXPERIMENTAL TUBERCULOSIS OF GUINEA PIGS
}

\author{
I. S. Mathur, H. P. Gupta, S. K. Srivastava S. Singh*, Khanna Madhu* and \\ N. M. KHANNA*
}

\section{Divisions of Microbiology and ${ }^{*}$ Pharmaceutics, Central Drug Research Institute, Lucknow, 226001 , India}

\begin{abstract}
Summary. Conventional chemotherapy of tuberculosis and leprosy requires rifampicin to be administered orally. The long period of treatment and adverse side effects of the drug lead to poor compliance. To overcome this, subdermal implants incorporating rifampicin in pure and micro-encapsulated forms with biodegradable material were used as a new drug delivery system in experimental tuberculosis of guinea pigs. Two experiments were performed with $45-\mathrm{mg}$ and $100-\mathrm{mg}$ drug implants. Progress of infection was followed at intervals by studying necropsy scores and weights of the organs of predilection and levels of the drug in the blood were determined. There was a constant and sustained release of the drug in therapeutic concentrations for 30 and 50 days until the implants were completely assimilated without causing any damage to the implant site. The importance of multiple implants at long intervals is discussed.
\end{abstract}

\section{INTRODUCTION}

The therapeutic efficacy of various potent anti-tuberculosis drugs has brought tuberculosis within the ambit of curable diseases, provided that the optimal conditions of therapy are adhered to. The long period of treatment with the conventional drug delivery systems often leads to discontinuation of treatment by a substantial proportion of patients as soon as they begin to feel better (Pamra, 1979).

Rifampicin, one of the most potent and powerful mycobactericidal drugs is used mainly in intermittent therapy, both in tuberculosis and leprosy, because of its high cost and adverse side effects (Girling and Hitze, 1979; Jopling, 1983). In the present investigation, a new method of drug administration was employed in which biodegradable implants containing rifampicin were inserted under the dermis of experimentally-infected guinea pigs. 


\section{MATERIALS AND METHODS}

Preparation of implants. The implants incorporating rifampicin, micro-encapsulated rifampicin and a biodegradable material in the ratio $1: 2: 1$ were prepared according to the specifications given in a patent entitled 'A process for the manufacture of improved medicinal pellets for use as subdermal implants for controlled release of a drug for an extended period of time in a human or animal system' (Khanna et al., 1981).

Efficacy experiments. Two experiments were performed. Random-bred guinea pigs from the Institute colony, weighing $250-350 \mathrm{~g}$ were divided into groups of 10 to 20 animals each. One group in each experiment was kept as an untreated negative control, while other groups were given implants at various intervals before and after infection or were given the drug orally.

The implants were inserted through a small incision made on either side of the flank and pushed below the dermis approximately $1 \mathrm{~cm}$ away from the incision site which was then sutured. For oral therapy, rifampicin powder was first titurated with $0.1 \mathrm{~N} \mathrm{HCl}(1.0 \mathrm{ml}$ for each $1 \mathrm{~g}$ of drug) and suspended in carboxy methylcellulose $0.5 \%$. The appropriate quantity of the drug, depending on the body weight, was fed in $0.4-\mathrm{ml}$ amounts to each animal once a day using a blunt needle and syringe.

For infection, animals were given subcutaneous injections in the left groin with $0.1 \mathrm{ml}$ (wet weight) of Mycobacterium tuberculosis $\mathrm{H} 37 \mathrm{Rv}$ suspended in $0.1 \mathrm{ml}$ of $0.07 \mathrm{M}$ sodium phosphate $(p \mathrm{H} \mathrm{8.7)}$. The culture was maintained in the laboratory on Loẅenstein Jensen medium. The animals were killed at specified intervals and post-mortem examinations made. To assess the extent of the disease, a necropsy score of 0 to 4 was given to different organs of predilection, i.e, inguinal glands, spleen, liver and lungs (Gupta and Chakravarty, i.e, 1955), and the organ weights were recorded according to Gupta et al. (1958).

Estimation of rifampicin in blood. The concentration of the drug in the blood obtained from the hearts of animals under treatment at the time of death was estimated by high-performance liquid chromatography.

\section{RESULTS}

In the first experiment, 10 animals were allocated to each group. Implants containing rifampicin $45 \mathrm{mg}$ were inserted 56 and 28 days before infection, on the day of infection and 28 days after infection. One group was left untreated as negative controls. The experiment was terminated 90 days after infection but some animals died before the end of the experiment and were not taken into consideration. The remaining animals were killed and their necropsy scores and organ weights recorded.

Table I shows that a total necropsy score of $15 \cdot 6 \pm 0 \cdot 29(\mathrm{Max}=16 \cdot 0)$ was obtained in the untreated negative-control group. Animals which received rifampicin implants 56 and 28 days before infection, on the day of infection or 28 days after infection had total necropsy scores which were decreased by $21 \cdot 1,35 \cdot 9,71 \cdot 8$ and $63.5 \%$ respectively. The weights of the four organs conformed with the corresponding necropsy scores. Animals which received the implants on the day of infection or 28 days later showed a more than $50 \%$ decrease of disease when compared with the controls while the reduction was much less in the two groups treated before infection. This indicated that the release of drug from the implants remained at the therapeutic level for only about 30 days.

On the basis of the above results, the implant size was increased from 45 to $100 \mathrm{mg}$ of rifampicin per implant for the second experiment. The animals were divided into five groups of 20 each and implants inserted 10, 20 and 30 days after infection. One group was treated orally (positive control) and another was kept as an untreated negative control group. 


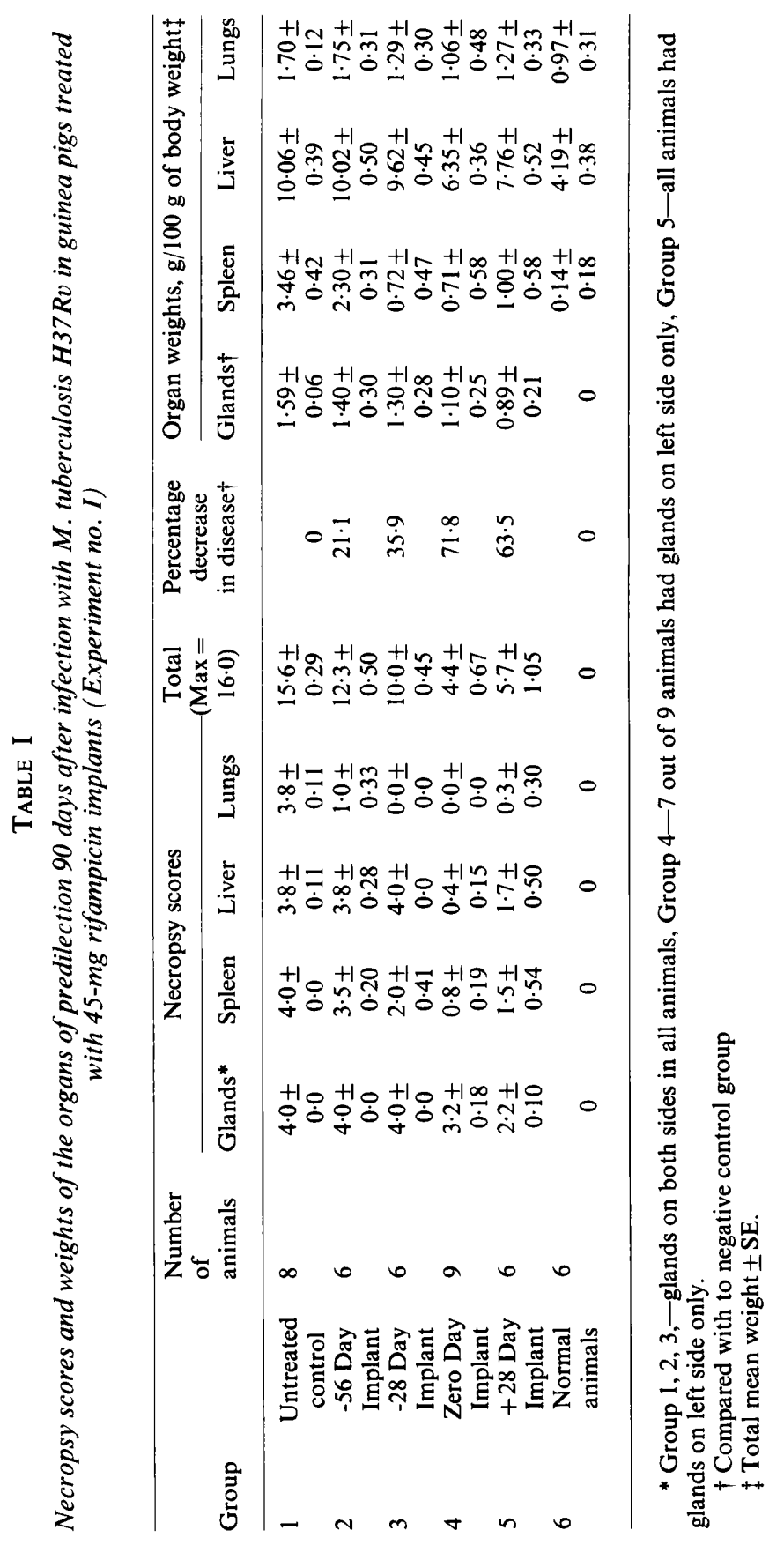


TABLE II

Necropsy scores and weights of organs of prediliction 40,60 and 80 days after infection with $M$ tuberculosis in guinea pigs with $100 \mathrm{mg}$ rifampicin implants (Experiment II)

\begin{tabular}{|c|c|c|c|c|c|c|c|c|c|c|c|c|}
\hline \multirow[b]{2}{*}{ Group } & & \multicolumn{4}{|c|}{ Necropsy scores } & \multirow{2}{*}{$\begin{array}{c}\text { Total } \\
(\mathrm{Max}= \\
16 \cdot 0)\end{array}$} & \multirow{2}{*}{$\begin{array}{l}\text { Percentage } \\
\text { decrease } \dagger \\
\text { in disease } \dagger\end{array}$} & \multirow{2}{*}{$\begin{array}{l}\text { Statis- } \\
\text { tical } \\
\text { analysis }\end{array}$} & \multicolumn{4}{|c|}{ Organ weights, $\mathrm{g} / 100 \mathrm{~g}$ of body weight } \\
\hline & & Glands & Spleen & Liver & Lungs & & & & Glands+ & Spleen & Liver & Lungs \\
\hline 1 & Control & $\begin{array}{c}3.67 \pm \\
0.258 \\
3.83 \pm \\
0.189 \\
4.00 \pm \\
0.0^{* *}\end{array}$ & $\begin{array}{c}1.40 \pm \\
0.22 \\
3.00 \pm \\
0.50 \\
4 \cdot 00 \pm \\
0.0\end{array}$ & $\begin{array}{c}2.00 \pm \\
0.31 \\
3.70 \pm \\
0.25 \\
4.00 \pm \\
0.0\end{array}$ & $\begin{array}{c}1 \cdot 17 \pm \\
0.30 \\
3 \cdot 00 \pm \\
0.24 \\
4.00 \pm \\
0.0\end{array}$ & $\begin{array}{c}8.25 \pm \\
0.63 \\
13.50 \pm \\
0.64 \\
16.00 \pm \\
0.0\end{array}$ & $\begin{array}{l}\cdots \\
\cdots \\
\cdots\end{array}$ & $\begin{array}{l}\ldots \\
\ldots \\
\cdots \\
\cdots\end{array}$ & $\begin{array}{c}0.40 \pm \\
0.21 \pm \\
0.55 \pm \\
0.32 \\
0.85 \pm \\
0.26\end{array}$ & $\begin{array}{c}1.08 \pm \\
0.28 \\
2.23 \pm \\
0.67 \\
1.99 \pm \\
0.67\end{array}$ & $\begin{array}{c}6.60 \pm \\
0.57 \\
7.47 \pm \\
1.26 \\
9.42 \pm \\
1.87\end{array}$ & $\begin{array}{c}1.20 \pm \\
0.21 \\
1.65 \pm \\
0.31 \\
1.09 \pm \\
0.32\end{array}$ \\
\hline 2 & $\begin{array}{c}+ \text { 10-Day } \\
\text { implant }\end{array}$ & $\begin{array}{c}1 \cdot 41 \pm \\
0.388 \\
2 \cdot 30 \pm \\
0.329 \\
2 \cdot 00 \pm \\
0.0^{* *}\end{array}$ & $\begin{array}{c}0.25 \pm \\
0.54 \\
0.50 \pm \\
0.21 \\
2.00 \pm \\
1.41\end{array}$ & $\begin{array}{c}0.50 \pm \\
0.34 \\
0.92 \pm \\
0.21 \\
2.00 \pm \\
1.41\end{array}$ & $\begin{array}{c}0.17 \pm \\
0.08 \\
0.20 \pm \\
0.31 \\
2.00 \pm \\
1.41\end{array}$ & $\begin{array}{c}2.33 \pm \\
0.75 \\
4.10 \pm \\
0.64 \\
8.00 \pm \\
6.00\end{array}$ & $\begin{array}{l}72 \cdot 0 \\
69 \cdot 6 \\
50 \cdot 0\end{array}$ & $\begin{array}{l}\mathrm{t}=3.2 \\
\mathrm{p} \quad 0.01 \\
\mathrm{t}=4.94 \\
\mathrm{p} \quad 0.001 \\
\mathrm{t}=3.27 \\
\mathrm{p} \quad 0.05\end{array}$ & $\begin{array}{c}0.17 \pm \\
0.08 \\
0.32 \pm \\
0.17 \\
0.25 \pm \\
0.12\end{array}$ & $\begin{array}{c}0.54 \pm \\
0.22 \\
0.87 \pm \\
0.38 \\
0.87 \pm \\
0.54\end{array}$ & $\begin{array}{r}4.48 \pm \\
0.37 \\
6.31 \pm \\
1.53 \\
4.72 \pm \\
0.92\end{array}$ & $\begin{array}{c}0.77 \pm \\
0.33 \\
1.04 \pm \\
0.28 \\
0.91 \pm \\
0.48\end{array}$ \\
\hline 3 & $\begin{array}{l}\text { +20-day } \\
\text { implant }\end{array}$ & $\begin{array}{c}1.41 \pm \\
0.518 \\
1.17 \pm \\
0.039 \\
2.40 \pm \\
0.24^{* *}\end{array}$ & $\begin{array}{c}0.17 \pm \\
0.10 \\
0.59 \pm \\
0.31 \\
1.20 \pm \\
0.65\end{array}$ & $\begin{array}{c}0.0 \pm \\
0.0 \\
0.41 \pm \\
0.33 \\
1.50 \pm \\
0.44\end{array}$ & $\begin{array}{c}0.08 \pm \\
0.08 \\
0.08 \pm \\
0.08 \\
1.20 \pm \\
0.37\end{array}$ & $\begin{array}{c}1.66 \pm \\
0.67 \\
2.24 \pm \\
0.49 \\
6.30 \pm \\
1.54\end{array}$ & $\begin{array}{l}80 \cdot 0 \\
83 \cdot 3 \\
60 \cdot 6\end{array}$ & $\begin{array}{l}t=3.67 \\
p \quad 0.01 \\
t=6.77 \\
p \quad 0.001 \\
t=5.24 \\
p \quad 0.001\end{array}$ & $\begin{array}{c}0.07 \pm \\
0.06 \\
0.12 \pm \\
0.08 \\
0.34 \pm \\
0.08\end{array}$ & $\begin{array}{c}0.24 \pm \\
0.13 \\
0.58 \pm \\
0.25 \\
0.64 \pm \\
0.34\end{array}$ & $\begin{array}{c}4.27 \pm \\
0.45 \\
4 \cdot 71 \pm \\
1.03 \\
5 \cdot 37 \pm \\
1.03\end{array}$ & $\begin{array}{c}0.78 \pm \\
0.38 \\
0.80 \pm \\
0.19 \\
0.91 \pm \\
0.23\end{array}$ \\
\hline 4 & $\begin{array}{l}\text { +30-day } \\
\text { implant }\end{array}$ & $\begin{array}{c}1.33 \pm \\
0.40 \mathrm{~s} \\
2.00 \pm \\
0.679 \\
2.50 \pm \\
0.58^{* *}\end{array}$ & $\begin{array}{c}0.08 \pm \\
0.08 \\
0.50 \pm \\
0.34 \\
0.44 \pm \\
0.72\end{array}$ & $\begin{array}{c}0.08 \pm \\
0.08 \\
0.30 \pm \\
0.19 \\
0.94 \pm \\
0.33\end{array}$ & $\begin{array}{c}0.0 \pm \\
0.0 \\
0.21 \pm \\
0.11 \\
0.50 \pm \\
0.22\end{array}$ & $\begin{array}{c}1.50 \pm \\
0.77 \\
3.00 \pm \\
0.87 \\
4.38 \pm \\
0.74\end{array}$ & $\begin{array}{l}84 \cdot 3 \\
77 \cdot 8 \\
72 \cdot 6\end{array}$ & $\begin{array}{l}\mathrm{t}=4.13 \\
\mathrm{p}=0.01 \\
\mathrm{t}=5.46 \\
\mathrm{p}=0.001 \\
\mathrm{t}=8.24 \\
\mathrm{p} \quad 0.001\end{array}$ & $\begin{array}{c}0.12 \pm \\
0.10 \\
0.20 \pm \\
0.06 \\
0.30 \pm \\
0.12\end{array}$ & $\begin{array}{c}0.28 \pm \\
0.15 \\
0.46 \pm \\
0.21 \\
0.46 \pm \\
0.28\end{array}$ & $\begin{array}{c}3.86 \pm \\
0.18 \\
4.42 \pm \\
0.93 \\
5.66 \pm \\
0.97\end{array}$ & $\begin{array}{c}0.82 \pm \\
0.54 \\
0.84 \pm \\
0.45 \\
1.00 \pm \\
0.56\end{array}$ \\
\hline 5 & $\begin{array}{l}+30 \text {-day } \\
\text { oral } \\
\text { therapy }\end{array}$ & $\begin{array}{c}3.17 \pm \\
0.40 \$ \\
1.67 \pm \\
0.54 \pm \\
3.00 \pm \\
0.33^{* *}\end{array}$ & $\begin{array}{c}0.83 \pm \\
0.21 \\
0.81 \pm \\
0.10 \\
0.54 \pm \\
0.70\end{array}$ & $\begin{array}{c}0.17 \pm \\
0.10 \\
0.0 \pm \\
0.0 \\
0.19 \pm \\
0.13\end{array}$ & $\begin{array}{c}0.0 \pm \\
0.0 \\
0.50 \pm \\
0.50 \\
0.25 \pm \\
0.16\end{array}$ & $\begin{array}{c}4.17 \pm \\
0.34 \\
2.33 \pm \\
0.64 \\
3.94 \pm \\
0.66\end{array}$ & $\begin{array}{l}50 \cdot 0 \\
82 \cdot 8 \\
74 \cdot 4\end{array}$ & $\begin{array}{l}\mathrm{t}=2.63 \\
\mathrm{p}=0.02 \\
\mathrm{t}=6.34 \\
\mathrm{p} \quad 0.001 \\
\mathrm{t}=8.86 \\
\mathrm{p} \quad 0.001\end{array}$ & $\begin{array}{c}0.21 \pm \\
0.13 \\
0.20 \pm \\
0.12 \\
0.46 \pm \\
0.23\end{array}$ & $\begin{array}{c}0.45 \pm \\
0.25 \\
0.37 \pm \\
0.17 \\
0.46 \pm \\
0.23\end{array}$ & $\begin{array}{c}4.94 \pm \\
0.46 \\
4.19 \pm \\
1.28 \\
4.00 \pm \\
0.63\end{array}$ & $\begin{array}{c}0.96 \pm \\
0.76 \\
0.90 \pm \\
0.67 \\
1.01 \pm \\
0.57\end{array}$ \\
\hline
\end{tabular}

Six animals from each of the five groups were killed 40,60 and 80 days after infection. Table II shows the necropsy scores and organ weights at each interval. The statistical analysis (students $t$ test) of the percentage inhibition of disease in groups 2,3 and 4 in comparison with the negative control (group 1) showed that the implants released the drug in therapeutic concentrations for 50-60 days. The necropsy scores and organ weights of the implanted groups were similar to those of the fifth group which was treated orally at a dose of $30 \mathrm{mg} / \mathrm{kg}$ /day for 6 days a week for the duration of the experiment.

\section{TABLE III}

Blood levels of rifampicin arising from implants of rifampicin or oral administration in guinea pigs infected with $M$. tuberculosis

Blood levels of rifampicin $(\mu \mathrm{g} / \mathrm{ml})^{*}$ on the given days after commencement of therapy

\begin{tabular}{|c|c|c|c|c|c|c|c|}
\hline \multirow[b]{2}{*}{ Treatment } & \\
\hline & 10 & 20 & 30 & 40 & 50 & 60 & 70 \\
\hline $\begin{array}{l}\text { Implants } \\
\text { (100 mg) } \\
\text { Oral }\end{array}$ & $\begin{array}{r}0.64 \\
\pm 0.12\end{array}$ & $\begin{array}{r}0.47 \\
\pm 0.05\end{array}$ & $\begin{array}{r}0.51 \\
\pm 0.05\end{array}$ & $\begin{array}{r}0.68 \\
\pm 0.15\end{array}$ & $\begin{array}{r}0.49 \\
\pm 0.08\end{array}$ & $\begin{array}{r}0.45 \\
\pm 0.09\end{array}$ & $\begin{array}{r}0.35 \\
\pm 0 \cdot 10\end{array}$ \\
\hline $\begin{array}{l}\text { (30 } \mathrm{mg} / \mathrm{kg} / \\
\text { day) }\end{array}$ & $\begin{array}{r}0.66 \\
\pm 0.04\end{array}$ & $\cdots$ & $\begin{array}{r}1.95 \\
\pm 0.12\end{array}$ & $\ldots$ & $\begin{array}{r}1.47 \\
\pm 0.05\end{array}$ & $\cdots$ & $\cdots$ \\
\hline
\end{tabular}

\footnotetext{
* Average of five animals.
} 
Table III shows the blood levels of rifampicin at various intervals in the implanted and orally-administered groups. The level in the implanted groups remained almost constant for 50-60 days after infection, thereafter, it declined.

\section{Discussion}

In both the experiments, complete suppression of disease was not obtained in any of the treated groups. This was in accordance with the results of Uvarova et al. (1976) who stated that even 5 months of oral treatment with rifampicin in guinea pigs at a dose of $30 \mathrm{mg} / \mathrm{kg} /$ day begining 3 weeks after experimental infection with $M$. tuberculosis failed to produce a complete recovery. Table I shows that a $45-\mathrm{mg}$ drug implant inserted 56 days before infection could decrease the disease score by only $21.1 \%$ in comparison with the control group showing that the release of drug from the implant in therapeutic levels lasted for less than 56 days. The second group given implants 28 days before infection showed a decrease of $39.5 \%$ in the disease score. However, the other two groups given implants on the day of and 28 days after infection showed decreases in the disease scores of the order of $71.8 \%$ and $63.5 \%$. The last group received the implant when the disease had progressed and showed a smaller decrease of disease. It can be argued therefore that therapeutic levels were maintained for 30-35 days by a 45-mg drug implant. Values of organ weights in table I corroborate this finding.

In the second experiment the implant size was increased to $100 \mathrm{mg}$ of drug per implant. The animals were given the implants 10,20 and 30 days after infection to simulate the conditions of mild, moderate and chronic infection respectively. When the first sub group of animals was killed 40 days after infection, the implants had been in place for 30, 20 and 10 days respectively. The orally-treated group had also received treatment for 10 days, but showed much less disease suppression when compared with the implanted groups, especially group 4 . This showed that the therapy by implants was better than by oral administration at that stage (table II).

Another subgroup of animals was killed 60 days after infection when the implants had been present for 50, 40 and 30 days (groups 2, 3 and 4; table II). At this stage the response to therapy, both by implants and by the oral route was highly effective $(\mathrm{p}<0.001)$. The total necropsy scores correlated well with the organ weights (table II) showing that the release of drug from implants was in the therapeutic range, as was the case with oral therapy.

The third and the final subgroup was killed 80 days after infection. By this time the implants had been in place for 70,60 and 50 days respectively. The groups having therapy for up to 60 and 50 days, including the orally-treated one, i.e., groups 3,4 and 5 , showed significantly lower total necropsy scores when compared with the negativecontrol group. This indicated that the drug was released within the therapeutic level for 50-60 days. The same picture was obtained by estimating drug levels in the blood (table III).

The above data show that biodegradable implants, each containing a total of 100 $\mathrm{mg}$ of rifampicin gave an almost uniformly sustained release of the drug for 50 days, at which time the implant had completely disappeared from its site without damaging the skin. On the basis of these data, the implants are at present undergoing toxicological studies in rabbits and monkeys in our Institute. Experiments with multiple implants for a longer duration of action are also in progress and these may lead to their use in clinical tuberculosis and leprosy. 


\section{REFERENCES}

Girling D J, Hitze K L 1979 Adverse reactions to rifampicin. Summary of adverse reactions. Bulletin of the World Health Organization 57: 45-49.

Gupta S K, Chakravarti R N 1955 The therapeutic activity of some sulphones and sulphoxides in experimental tuberculosis of guinea pigs. British Journal of Pharmacology 10: 113-115.

Gupta S K, Mathur I S, Mukherji B 1958 The effect of potential antimycobacterial agents on the lung, liver and spleen weights in 'short term' screening in experimental tuberculosis of guinea pigs. Proceeding Symposium on Chemotherapy 32-35.

Khanna N M Gupta S K Sarin J P S Singh S, Khanna M 1981 Subdermal sustained release pharmaceutical implants. Indian patent file No. 538/Del/81, Belgium Patent No. 208, 599, 1982, West Germany Patent No. 3228533, 1982, United Kingdom Patent No. 2103927A, 1983.

Jopling W H 1983 Side effects of anti-leprosy drugs in common use. Leprosy Review 54: 261-269.

Pamra S P 1979 Chemotherapy of pulmonary tuberculosis: Present status. Indian Journal of Tuberculosis 26: 106-120.

Uvarova O A, Kozulitsyna T I, Korotaev G A 1976 Characteristics of the effect of rifampicin on experimental tuberculosis. Problemy. Tuberkuleza (1): 65-70 (in Russian) quoted from Chemical Abstracts 1976, 84: 144805Y. 